\title{
CT-guided aspiration lung biopsy for EGFR and ALK gene mutation analysis of lung cancer
}

\author{
WEISHENG LIAN ${ }^{1}$ and YONG OUYANG ${ }^{2}$ \\ ${ }^{1}$ Department of Intervention, Zhejiang Cancer Hospital, Hangzhou, Zhejiang 310022 ; ${ }^{2}$ Department of Vascular Surgery, \\ Hangzhou First People's Hospital of Fuyang, Hangzhou, Zhejiang 311499, P.R. China
}

Received August 17, 2016; Accepted February 6, 2017

DOI: $10.3892 / \mathrm{ol} .2017 .5921$

\begin{abstract}
The present study investigated the rates of detection and the positive rates of computed tomography (CT)-guided aspiration of lung biopsy for epidermal growth factor receptor (EGFR) gene and anaplastic lymphoma kinase (ALK) gene, and analyzed the relationship between gene mutation and clinical characteristics to improve the rate of related factors of gene detection. The clinical data and CT-guided aspiration biopsy specimen of 250 patients with lung cancer. Data showed that the rate of EGFR gene mutation was $41.2 \%$ (103/250) in biopsy specimens of non-small cell lung cancer patients. The rate of EGFR gene mutation of adenocarcinoma $(56.6 \%$, $\mathrm{P}<0.01)$ was higher than other types of lung cancer. ALK gene mutation of patients in phase IV was obviously higher than that of patients not in phase IV $(18.5$ and $1.8 \%, \mathrm{P}<0.01)$. The rate of EGFR gene detection was $83.2 \%$ (208/250). The rate of detection of tumor cells $>50$ was higher. The rate of ALK protein immunohistochemical detection was $87.2 \%$, and the rate of coarse needle biopsy detection was higher than that of the fine needle (91 and $72 \%, \mathrm{P}<0.01$ ), but the positive rate between coarse needle biopsy and fine needle biopsy had no difference $(\mathrm{P}>0.05)$. The rate of detection was associated with tumor cell number $(\mathrm{P}<0.05)$, and had no correlation with the proportion of tumor cells $(\mathrm{P}>0.05)$. The rate of detection of EGFR and ALK genes was associated with tumor cell number and had no correlation with the proportion of tumor cells. The rate of detection is higher when the number of tumor cells is more than 50 .
\end{abstract}

\section{Introduction}

Lung cancer is the most common malignant tumor globally. According to the data of the World Health Organization (WHO) in 2008, death toll caused by lung cancer was

Correspondence to: Dr Yong Ouyang, Department of Vascular Surgery, Hangzhou First People's Hospital of Fuyang, 4 Huancheng Bei Road, Fuchun Street, Hangzhou, Zhejiang 311499, P.R. China E-mail: ouyang_yong1@163.com

Key words: lung cancer, gene mutation, biopsy specimen, epidermal growth factor receptor, anaplastic lymphoma kinase
1.38 million all over the world each year, ranking the first in all malignant tumors (1). In 2005, the new cases of lung cancer in China were $\sim 500,000$ cases, including $\sim 330,000$ cases of males and 170,000 cases of females. Epidemiological study pointed out that lung cancer caused 89,200 deaths in urban and rural areas in China in 2009 (2). Therefore, studies on early lung cancer have very important medical and social significance (3). Non-small cell lung cancer (NSCLC) refers to all types of lung cancer except for small cell lung cancer. Its incidence accounts for $\sim 80 \%$ of the total cases of lung cancer, among which $\sim 2 / 3$ of patients have distant metastases. In case of lack of anticancer treatment, their mean survival time is 4-5 months (1). Chemotherapy is the main treatment means, but the prognosis remains poor (4). NSCLC consists of three types, namely adenocarcinoma, squamous carcinoma and large cell carcinoma, among which adenocarcinoma is a more common tissue type (5).

In recent years, individualized treatment with molecular targeted therapy as the core content has become the research hotspot of lung cancer treatment and the detection of driver genes related to lung cancer has attracted increased attention $(6,7)$. The epidermal growth factor receptor (EGFR) gene and anaplastic lymphoma kinase (ALK) fusion gene are the two driver genes proved in NSCLC $(8,9)$. Their corresponding targeted drugs, including tyrosine kinase inhibitor (TKI) and crizotinib show good curative effects in clinical studies $(10,11)$. Two phase III prospective randomized clinical trials showed that as a first-line treatment means, TKI gefitinib could more effectively prolong the progression-free survival (PFS) of patient, compared with chemotherapy protocol based on platinum PFS $(12,13)$. Overall response rate of crizotinib to the phase I clinical trial treatment of ALK positive NSCLC patients reached $64 \%$ (14). Based on the test results of PROFILE 1001 and PROFILE 1005, the indications of crizotinib in ALK positive advanced NSCLC obtained accelerated approval by the U.S. Food and Drug Administration (FDA) in August 2011 (10).

Many studies showed that the utilization of corresponding targeted drug treatment of molecular targets for gene variation patients could not only prolong PFS obviously, but also significantly improve living quality, compared with chemotherapy (7). At present, all guidelines recommend that EGFR and ALK detection should be conducted before treatment so as to benefit patients from targeted drug treatment as soon 
as possible. In NCCN Guidelines 2014, EGFR and ALK detection of non-squamous carcinoma were listed in class 1 evidence recommending, while non-smoking squamous carcinoma should also take the detection of EGFR and ALK genes into consideration. With the rapid development of molecular biology and the maturity of gene detection technology, the effects of molecular targeted drugs in lung cancer treatment have been paid more and more attention and its curative effects were also recognized in the clinic, so it is necessary to improve the clinical gene detection.

Computed tomography (CT)-guided percutaneous lung aspiration biopsy has been widely used in clinic and has become important for the diagnosis and differential diagnosis of refractory lung diseases. For patients with advanced lung cancer who are not suitable for operation, cytological specimens may be the important source for their EGFR and ALK gene mutation detection. However, such invasive examination has many complications at present. Some clinical practices found that the clinical complications of CT-guided fine needle aspiration biopsy were much less than those of coarse needle aspiration biopsy. Under the premise of ensuring the rate of detection of certain gene, the utilization of fine needle aspiration biopsy for specimens applicable to fine needle aspiration could not only reach the target of gene detection, but also reduce clinical complications. From the perspective of application, small specimens (including lung aspiration and bronchoscope specimens) had greater application prospect. The rate of mutation of EGFR gene in Asian patients with lung adenocarcinoma was $\sim 60.5 \%$ and the rate of expression of EML4/ALK fusion gene in Asian patients with NSCLC was $10 \%(15,16)$.

Scorpion amplification refractory mutation system (Scorpion ARMS) is applied in the detection of EGFR gene mutation. It is a new technology that combines ARMS and Scorpion PCR technologies. Scorpion probe can detect mutant gene with the content as low as $1 \%$ in samples, with the characteristics of high sensitivity and strong specificity. It is especially suitable for aspiration and cytological specimens with less tumor cells (17).

At present, there are three methods for the detection of ALK fusion gene, namely based on PCR amplification technology, fluorescence in situ hybridization (FISH) and immunohistochemistry (IHC) (18). By virtue of the advantages, including simple operation and low price, IHC becomes the important method used for ALK detection at present. Ventana IHC has been approved to be used in the detection of ALK fusion gene by the European Union, China and other countries. Many studies also showed that Ventana IHC method and FISH method have high coherence in sensitivity and specificity (19). Moreover, compared with FISH detection method, Ventana detection was more efficient (the detection could be finished within $48 \mathrm{~h}$ generally) and it is relatively inexpensive, and has low requirements for detection personnel. The detection could be performed under a light microscope and the structure of tumor tissues and histological patterns of tumor cells could also be observed simultaneously. Due to the application of two-spot interpretation method, this method greatly reduced the effects of subjective factors on results $(20,21)$. Therefore, this study applied Scorpion ARMS method and Ventana ALK (D5F3) IHC method, respectively, in the screening of EGFR and ALK fusion genes.
We conducted CT-guided coarse/fine needle aspiration for the detection of EGFR gene and ALK gene for 250 cases of NSCLC patients and analyzed the relationship between clinical characteristics and gene mutation so as to specify the rate of detection and the positive rate of CT-guided coarse/fine needle aspiration biopsy specimen used for gene detection and improve the rate of relevant factors of detection.

\section{Patients and methods}

Patients. The clinical data and CT-guided aspiration biopsy specimen of 250 patients with lung cancer admitted in Zhejiang Cancer Hospital from June 2014 to August 2015 were collected. Appropriate aspiration needles were selected according to tumor location and size, including 50 cases of fine needle aspiration and 200 cases of coarse needle aspiration. Clinical data included admission number, pathology number, age, gender, smoking history, clinical stages and pathological results (including pathological patterns, differentiation degree and IHC results). Appropriate aspiration needles were selected according to tumor location and size. Coarse needle applied BioPince 17-gauge coaxial automatic biopsy needle or Precisa 18- and 16-gauge semi-automatic biopsy needles to conduct aspiration biopsy, while fine needle applied Precisa 20-gauge semi-automatic biopsy needle or Cook 19-gauge coaxial semi-automatic biopsy needles (Shengdi Medical Instrument Company, Beijing, China) to conduct aspiration biopsy. This study was approved by the Ethics Committee of Zhejiang Cancer Hospital. All specimens were obtained before treatment and the patients or their families signed informed consent form for aspiration.

\section{Research methods}

CT-guided percutaneous aspiration biopsy. Percutaneous coarse/fine needle aspiration was conducted under the guidance of large-aperture spiral CT (Siemens AG, Berlin, Germany). Appropriate position was selected according to lesion location and the scanning area depending on the area of the lesion. CT scanning parameters: $120 \mathrm{kV}$ for tube voltage, $220 \mathrm{~mA}$ for tube current, $5 \mathrm{~mm}$ for section thickness and 1.0 for guided pitch. Aspiration point was determined by applying metal mark locating method so as to avoid rib or scapula and substantial lesion was selected according to CT values. The fine needle applied Cook 19-gauge coaxial semi-automatic biopsy needle or Precisa 20-gauge semi-automatic biopsy needle, while coarse needle applied BioPince 17-gauge coaxial automatic biopsy needle or Precisa 18- and 16-gauge semi-automatic biopsy needles. The distance, depth and angle of needle insertion were measured. After routine disinfection, darpe and local anaesthesia, positioning aspiration was conducted to obtain tissues. After aspiration, CT scanning was repeated so as to obtain information whether there was pneumothorax, bleeding or other complications.

Specimen processing. Fine or coarse needle aspiration specimen was made into a cell wax block for use through fixing in $4 \%$ neutral formalin and embedding in paraffin. Before gene detection, whether the quantity and ratio of tumor cells in cell sections in each case of aspiration specimen met standards was observed. The ratio of tumor cells was calculated by average ratio of the number of specimen in hematoxylin and 
eosin (H\&E) section counting tumor cells under an ordinary light microscope (Olympus, Tokyo, Japan) to the number of nucleated cells and the ratio of tumor cells, respectively, counted in 5 high-power fields (x400) selected from the most enriched area of tumor cells. In case the number of highpower fields did not reach 5 , the average value of tumor cell ratios was taken according to actual number of fields, among which the absolute value of tumor cells counted in the field with the highest ratio was taken. The above were interpreted and recorded independently by two researchers, and then the results were checked. In case of inconsistent results, they were decided through consultation or interpreted by a third researcher.

EGFR gene mutation detected by ARMS method. The remaining tissues of the specimens obtained from $C T$-guided lung cancer aspiration biopsy after pathological diagnosis were used for EGFR gene detection. Eight to ten pieces of paraffin with the section thickness of 5-8 $\mu \mathrm{m}$ were cut from paraffin-embedded tissues, wrapped and put into a $1.5-\mathrm{ml}$ centrifuge tube. In case of slicing, the slicing knife was disinfected with $75 \%$ alcohol between cases so as to prevent cross contamination. A piece of H\&E staining section should be cut simultaneously from all specimens so as to judge the content of tissues in tumor cells. Tissue DNA was extracted and its concentration was measured by ultramicrospectrophotometer (Nano Photonics, Shanghai, China). The EGFR gene of aspiration specimens was detected by Scorpion ARMS (Gemma Gene Co., Shanghai, China). Moreover, the relationship between the number and ratio of clinical tumor cells and the rate of detection of specimens was analyzed. The clinicopathological characteristics of positive and negative patients with EGFR gene mutation were compared.

Detection of ALK expression by IHC. The remaining tissues from clinicopathological diagnosis were used. Six to eight pieces with the thickness of 3-5 $\mu \mathrm{m}$ were cut from paraffin-embedded tissues. In case of slicing, the slicing knife was disinfected with $75 \%$ alcohol between cases so as to prevent cross contamination. A piece of H\&E staining section should be cut simultaneously from all specimens so as to judge the content of tissues in tumor cells. The ALK expression of 250 cases of aspiration specimens was detected by Ventana ALK (D5F3) IHC method (11). Moreover, the relationship between the number and ratio of clinical tumor cells and the rate of detection of small specimens was analyzed. The clinicopathological characteristics of positive and negative patients with ALK gene mutation were compared.

Data collection. Two hundred and fifty cases of small biopsy specimen from June 2014 to August 2015 in Zhejiang Cancer Hospital were collected, among them, 50 cases were with fine needle biopsy specimens and 200 cases with coarse needle biopsy specimens under CT-guidance. Of the 50 cases with fine needle biopsy specimens, 29 cases were male and 21 cases were female; aged from 22 to 84 years, with a median age of 63 years, 21 cases were older than 60 years, 29 cases were younger than 60 years. Of the 200 cases with coarse needle biopsy specimens, 127 cases were male and 73 cases were female; aged from 26 to 81 years, with a median age of 59 years, 101 cases were older than 60 years, 99 cases were younger than 60 years.
Table I. EGFR gene mutation in 250 cases of lung cancer aspiration biopsy by ARMS method (cases).

\begin{tabular}{llcc}
\hline Position & Mutation type & Cases (n) & $\begin{array}{c}\text { Percentage to all } \\
\text { mutations (\%) }\end{array}$ \\
\hline Exon 19 & Deletion & 46 & 44.7 \\
Exon 21 & L858R mutation & 41 & 39.8 \\
Exon 21 & L861Q mutation & 3 & 2.9 \\
Exon 18 & G719X mutation & 3 & 2.9 \\
Exon 20 & T790M mutation & 3 & 2.9 \\
Double & 19 deletion/L858R & 4 & 3.9 \\
mutation & mutation & & \\
Double & G719X/L858R & 3 & 2.9 \\
mutation & mutation & & \\
Total & & 103 & 41.2 \\
\hline
\end{tabular}

EGFR, epidermal growth factor receptor; ARMS, amplification refractory mutation system.

Statistical analysis. Relationship between detected patients and non-detected patients, ALK-positive/negative with clinical pathological characteristics was analyzed, dichotomous variable adopted the square test, comparison between groups was analyzed by t-test. Continuous variable was tested by Wilcoxon rank-sum test. The above statistical analysis was carried out with SPSS 17.0 (IBM, Armonk, NY, USA), measurement data were expressed by mean $\pm \mathrm{SD}$. $\mathrm{P}<0.05$ was considered to indicate a statistically significant difference.

\section{Results}

General conditions. CT-guided fine needle aspiration biopsy for all patients achieved success and the length of tumor obtained through aspiration was $0.5-1.5 \mathrm{~cm}$. There were 50 cases applied Cook 19-gauge coaxial biopsy needle or Precisa 20-gauge semi-automatic biopsy needle, and 200 cases applied BioPince 17-gauge automatic biopsy needle or Precisa 18- and 16-gauge semi-automatic biopsy needles. Complications after aspiration: Pneumothorax at different levels was found in 16 cases of coarse needle aspiration $(8 \%$, $16 / 200)$, among which the degree of pneumothorax of 6 cases $(3 \%, 6 / 200)>20 \%$ of single lung and that was relieved after vacuum sealing drainage. The other cases improved through self-absorption. Thirty-one cases $(15.5 \%, 31 / 200)$ had errhysis at different levels in needle passage and lesion area, as well as hemoptysis symptom. They were all relieved after giving medical hemostatic treatment. Among 50 cases of fine needle aspiration, only 2 cases had a small amount of pneumothorax and 3 cases had a little errhysis in needle passage. The absence of complaints after observing for 2-4 h confirmed that no further treatment was needed.

\section{Detection of EGFR gene in CT-guided aspiration biopsy specimen of lung cancer}

EGFR gene mutation in lung cancer aspiration biopsy detected by ARMS method. Among 250 cases of small biopsy specimens of lung cancer, a total of 103 cases were detected 
Table II. Relationship between EGFR gene mutation and clinical pathological characteristics (cases).

\begin{tabular}{lcc}
\hline $\begin{array}{l}\text { Clinical } \\
\text { characteristics }\end{array}$ & $\begin{array}{c}\text { With EGFR } \\
\text { mutation }\end{array}$ & $\begin{array}{c}\text { Without EGFR } \\
\text { mutation }\end{array}$ \\
\hline $\begin{array}{l}\text { Gender } \\
\text { Male }\end{array}$ & 39 & 117 \\
Female & 64 & 30 \\
Age (years) & & \\
$\geq 60$ & 51 & 71 \\
$<60$ & 52 & 76 \\
Smoking history & & \\
Yes & 30 & 90 \\
No & 73 & 57 \\
Phase & & 99 \\
I-III & 74 & 48 \\
IV & 29 & 72 \\
Histological type & & 56 \\
Adenocarcinoma & 94 & 72 \\
Squamous carcinoma & 3 & \\
Adenosquamous carcinoma & 3 & \\
Others & 3 & \\
\hline
\end{tabular}

EGFR, epidermal growth factor receptor.

to have EGFR gene mutation, with the mutation rate of $41.2 \%$, among which single-site mutation accounted for $93.2 \%$ and double-site mutation accounted for $6.8 \%$. The most common mutation included exon 19 deletion and exon 21 L858R mutation and mutation was rare in the others (Table I).

Relationship between EGFR gene mutation and clinical pathological characteristics. The results of detection of the mutation of EGFR gene for 250 cases of NSCLC showed that the rate of EGFR gene mutation in female patients $(62.1 \%$, 64/94) was significantly higher $(\mathrm{P}<0.01)$ than that of male patients $(37.9 \%, 39 / 156)$. The rate of the mutation of EGFR gene in non-smoking patients $(56.2 \%, 73 / 130)$ was significantly higher $(\mathrm{P}<0.01)$ than that of smoking patients $(25 \%$, $30 / 120)$. There were no differences in the rates of gene mutation at the age of 60 years or above. In histological types, there were 94 cases of patients with EGFR detected with mutation of 166 cases of lung adenocarcinoma, accounting for $56.6 \%$. There were 3 cases of patients with EGFR mutation in 59 cases of squamous cell carcinoma, accounting for $5.1 \%$. There were 3 cases of patients with EGFR mutation in 10 cases of squamous carcinoma. EGFR gene mutation (3/15) was detected in other types of lung cancer and the rate of EGFR gene mutation in patients with adenocarcinoma was significantly higher than that of squamous carcinoma and other types of lung cancer $(\mathrm{P}<0.01)$ (Table II).

Comparison of the rate of detection and positive rate of EGFR gene by percutaneous coarse/fine needle aspiration biopsy. The detection of the mutation of EGFR gene was conducted for 250 cases of NSCLC lung cancer with the rate of detection of $83.2 \%(208 / 250)$ and the positive rate of $41.2 \%$, (103/250). Appropriate aspiration needle was selected according to mass location and size. Among 250 cases of patients, 200 cases were conducted with CT-guided coarse needle aspiration and 50 cases with fine needle aspiration. The results of the rate of detection showed that the rate of detection of CT-guided coarse needle biopsy aspiration $(91 \%$, $182 / 200)$ was significantly $(\mathrm{P}<0.01)$ higher than that of fine needle $(52 \%, 26 / 50)$. The positive rate $(45.5 \%, 91 / 200)$ was significantly higher $(\mathrm{P}<0.01)$ than that of fine needle $(24 \%$, 12/50) (Tables III and IV).

Relationship between the number and ratio of tumor cells and the rate of detection of EGFR. The detection of the mutation of EGFR gene was conducted for 250 cases of NSCLC (with the rate of detection of $83.2 \%, 208 / 250)$. CT-guided

Table III. Comparison of rate of detection of EGFR by percutaneous coarse/fine needle aspiration biopsy (cases).

\begin{tabular}{lcccc}
\hline Aspiration needle & Cases & Detected & Not detected & Percentage \\
\hline Coarse needle & 200 & 182 & 18 & 91.0 \\
Fine needle & 50 & 26 & 24 & 52.0 \\
Total & 250 & 208 & 42 & 83.2 \\
\hline
\end{tabular}

${ }^{a} \mathrm{P}<0.01$, the differences were statistically significant. EGFR, epidermal growth factor receptor.

Table IV. Comparison of EGFR positive rate by percutaneous coarse/fine needle aspiration biopsy (cases).

\begin{tabular}{lrrrr}
\hline Aspiration needle & Cases & Positive & Negative & Percentage \\
\hline Coarse needle & 200 & 91 & 109 & 45.5 \\
Fine needle & 50 & 12 & 38 & 24.0 \\
Total & 250 & 103 & 147 & 41.2 \\
\hline
\end{tabular}

${ }^{\mathrm{a}} \mathrm{P}<0.01$, the differences were statistically significant. EGFR, epidermal growth factor receptor. 
Table V. Relationship between the number and ratio of tumor cells and the rate of detection of EGFR of small specimens (cases).

\begin{tabular}{|c|c|c|c|c|c|}
\hline Aspiration needle & Cases & $\begin{array}{l}\text { No. of tumor cells } \\
\quad(\text { mean } \pm \text { SD })\end{array}$ & $\begin{array}{l}\text { No. of tumor } \\
\text { cells }(\geq 50)\end{array}$ & $\begin{array}{l}\text { Ratio of tumor } \\
\text { cells }(\geq 10 \%)\end{array}$ & $\begin{array}{c}\text { Rate of } \\
\text { detection }(\%)\end{array}$ \\
\hline Coarse needle & 200 & $51.67 \pm 25.43$ & 138 & 195 & 91.0 \\
\hline Fine needle & 50 & $37.65 \pm 18.14^{\mathrm{a}}$ & $21^{\mathrm{b}}$ & $48^{c}$ & 52.0 \\
\hline
\end{tabular}

${ }^{\mathrm{a}} \mathrm{P}<0.01$ and ${ }^{\mathrm{b}} \mathrm{P}<0.05$, the differences were statistically significant. ${ }^{\mathrm{c}} \mathrm{P}>0.05$, the differences were not statistically significant. EGFR, epidermal growth factor receptor.

coarse needle aspiration was conducted for 200 cases of patients with NSCLC. The results showed that the number of tumor cells of specimen was $51.67 \pm 25.43$. There were 138 cases with the number of tumor cells of $\geq 50$ and there were 195 cases with the ratio of tumor cells of $\geq 10 \%$. Among 50 cases of patients conducted with fine needle aspiration, the number of tumor cells of specimen was $37.65 \pm 18.14$. There were 33 cases with the number of tumor cells of $\geq 50$ and there were 48 cases with the ratio of tumor cells of $\geq 10 \%$. The results of the rate of detection of EGFR gene showed that the rate of detection of CT-guided coarse needle biopsy aspiration was higher $(\mathrm{P}<0.05)$ than that of fine needle. This was relevant to that of the number of tumor cells by coarse needle aspiration, which was more than that of tumor cells by fine needle aspiration $(\mathrm{P}<0.05)$, while it was irrelevant to the non-significant ratio of tumor cells of coarse and fine needles (Table V).

Detection of ALK gene in CT-guided aspiration biopsy specimen of lung cancer

ALK gene mutation in lung cancer aspiration biopsy detected by IHC method. Among 250 cases of small biopsy specimens of lung cancer, a total of 15 cases were detected to have ALK gene mutation, with the mutation rate of $6 \%$, the ALK gene expression rate of Chinese patients with lung adenocarcinoma was $8.0 \%$, and the rate of detection of patients with the number of tumor cells of more than 100 was higher $(\mathrm{P}<0.001)$.

Relationship between ALK gene mutation and clinicopathological characteristics. In our study, the correlation between ALK gene expression and age and pathological differentiation degree, was not found. Fifteen cases of patients with positive ALK gene were all non-smokers and patients with adenocarcinoma. ALK gene mutation of phase IV patients $(18.5 \%, 12 / 65)$ was higher $(\mathrm{P}<0.05)$ than that of non-phase IV patients $(1.8 \%, 3 / 170)$ (Table VI).

Comparison of the rate of detection and positive rate of ALK gene by percutaneous coarse/fine needle aspiration biopsy. ALK IHC detection was conducted for 250 cases of NSCLC (with the rate of detection of $87.2 \%, 218 / 250$; the positive rate of $6 \%, 15 / 250)$. The results of detection showed that the rate of ALK CT-guided coarse needle biopsy aspiration $(91 \%, 182 / 200)$ was very significantly higher $(\mathrm{P}<0.01)$ than that of fine needle $(72 \%, 36 / 50)$. The rate of positive ALK $(6.5 \%, 13 / 200)$ was consistent with that of fine needle $(4 \%$, $2 / 50)$ and the differences were not statistically significant (P>0.05) (Tables VII and VIII).

Relationship between the number and ratio of tumor cells and the rate of detection of EGFR. The detection of ALK
Table VI. Relationship between ALK gene mutation and clinical pathological characteristics (cases).

\begin{tabular}{|c|c|c|c|}
\hline Clinical characteristics & $\begin{array}{l}\text { With ALK } \\
\text { mutation }\end{array}$ & $\begin{array}{l}\text { Without ALK } \\
\text { mutation }\end{array}$ & P-value \\
\hline \multicolumn{4}{|l|}{ Gender } \\
\hline Male & 6 & 150 & \multirow[t]{2}{*}{$0.065^{\mathrm{b}}$} \\
\hline Female & 9 & 85 & \\
\hline \multicolumn{4}{|l|}{ Age (years) } \\
\hline$\geq 60$ & 6 & 116 & \multirow[t]{2}{*}{$0.482^{b}$} \\
\hline$<60$ & 9 & 119 & \\
\hline \multicolumn{4}{|l|}{ Smoking history } \\
\hline Yes & 15 & 105 & \multirow[t]{2}{*}{$<0.001^{\mathrm{a}}$} \\
\hline No & 0 & 130 & \\
\hline \multicolumn{4}{|l|}{ Phase } \\
\hline I-III & 3 & 170 & \multirow[t]{2}{*}{$<0.001^{\mathrm{a}}$} \\
\hline IV & 12 & 65 & \\
\hline \multicolumn{4}{|l|}{ Histological type } \\
\hline Adenocarcinoma & 15 & 151 & \multirow[t]{3}{*}{$<0.001^{\mathrm{a}}$} \\
\hline Squamous carcinoma & 0 & 59 & \\
\hline $\begin{array}{l}\text { Adenosquamous } \\
\text { carcinoma }\end{array}$ & 0 & 10 & \\
\hline Other & 0 & 15 & \\
\hline \multicolumn{4}{|l|}{$\begin{array}{l}\text { Pathological } \\
\text { differentiation degree }\end{array}$} \\
\hline Poorly & 6 & 112 & \multirow[t]{3}{*}{$0.824^{\mathrm{b}}$} \\
\hline Moderately & 4 & 50 & \\
\hline Well & 5 & 73 & \\
\hline
\end{tabular}

${ }^{\mathrm{a}} \mathrm{P}<0.01$, the differences were statistically significant. ${ }^{\mathrm{b}} \mathrm{P}>0.05$, the differences were not statistically significant. ALK, anaplastic lymphoma kinase.

gene mutation was conducted for 250 cases of NSCLC (with the rate of detection of $87.2 \%, 218 / 250$ ). CT-guided coarse needle aspiration was conducted for 200 cases of patients with NSCLC. The results showed that the number of tumor cells of specimen was $51.67 \pm 25.43$. There were 138 cases with the number of tumor cells of $\geq 50$, and there were 195 cases with the ratio of tumor cells of $\geq 10 \%$. Among 50 cases of patients conducted with fine needle aspiration, the number of tumor cells of specimen was $37.65 \pm 18.14$, there were 33 cases with the number of tumor cells of $\geq 50$, and there were 48 cases 
Table VII. Comparison of the rate of detection of ALK by percutaneous coarse/fine needle aspiration biopsy (cases).

\begin{tabular}{lccccc}
\hline Aspiration needle & Cases & Detected & Not detected & Percentage & P-value \\
\hline Coarse needle & 200 & 182 & 18 & 91.0 & $<0.001^{\text {a }}$ \\
Fine needle & 50 & 36 & 14 & 72.0 & 87.2 \\
Total & 250 & 218 & 32 & \\
\hline
\end{tabular}

${ }^{\mathrm{a}} \mathrm{P}<0.01$, the differences were statistically significant. ALK, anaplastic lymphoma kinase.

Table VIII. Comparison of ALK positive rate by percutaneous coarse/fine needle aspiration biopsy (cases).

\begin{tabular}{lrcccr}
\hline Aspiration needle & Cases & Positive & Negative & Percentage & P-value \\
\hline Coarse needle & 200 & 13 & 187 & 6.5 & $0.742^{\mathrm{a}}$ \\
Fine needle & 50 & 2 & 48 & 4.0 & 6.0 \\
Total & 250 & 15 & 235 & &
\end{tabular}

${ }^{a} \mathrm{P}>0.05$, the differences were not statistically significant. ALK. anaplastic lymphoma kinase.

Table IX. Relationship between the number and ratio of tumor cells and the rate of detection of EGFR.

\begin{tabular}{lccccc}
\hline Aspiration needle & Cases & $\begin{array}{c}\text { No. of tumor } \\
\text { cells (mean } \pm \text { SD) }\end{array}$ & $\begin{array}{c}\text { No. of tumor } \\
\text { cells }(\geq 50)\end{array}$ & $\begin{array}{c}\text { Ratio of tumor } \\
\text { cells }(\geq 10 \%)\end{array}$ & $\begin{array}{c}\text { Rate of } \\
\text { detection }(\%)\end{array}$ \\
\hline Coarse needle & 200 & $51.67 \pm 25.43$ & 138 & 195 & 41 \\
Fine needle & 50 & $37.65 \pm 18.14^{\mathrm{a}}$ & $21^{\mathrm{b}}$ & $48^{\mathrm{c}}$ & 72 \\
\hline
\end{tabular}

${ }^{\mathrm{a}} \mathrm{P}<0.01$ and ${ }^{\mathrm{b}} \mathrm{P}<0.05$, the differences were statistically significant. ${ }^{\mathrm{P}} \mathrm{P}>0.05$, the differences were not statistically significant. EGFR, epidermal growth factor receptor.

with the ratio of tumor cells of $\geq 10 \%$. The results on the rate of detection of ALK gene showed that the rate of detection of CT-guided coarse needle biopsy aspiration was higher than that of fine needle $(\mathrm{P}<0.01)$, which was relevant to the number of tumor cells by coarse needle aspiration was more than that of tumor cells by fine needle aspiration $(\mathrm{P}>0.05)$, while it was irrelevant for the ratio of tumor cells of coarse and fine needles $(\mathrm{P}>0.05$, the differences were not statistically significant) (Table IX).

\section{Discussion}

By virtue of the advantages, including minimally invasive, easy and simple to handle and less complications, CT-guided percutaneous lung aspiration biopsy has been widely used in clinic (22). Many clinical patients with advanced NSCLC have lost the opportunity of surgical therapy and lung aspiration biopsy is an important means to specify diagnosis (23). The implementation of molecular detection can also further specify the type of gene mutation so as to guide the next step of treatment. Compared with surgical specimens, the number and ratio of tumor cells contained in aspiration biopsy specimens were lower (24). The improvement of the rate of detection of clinical aspiration will be helpful in clinical diagnosis and treatment.
In our study, CT-guided aspiration biopsy for 250 cases of NSCLC patients achieved success and the length of tumor obtained through aspiration was $0.5-1.5 \mathrm{~cm}$. There were 50 cases applied Cook 19-gauge coaxial biopsy needle or Precisa 20-gauge semi-automatic biopsy needle, and 200 cases applied BioPince 17-gauge automatic biopsy needle. Complications of fine needle after aspiration were significantly less. Among 50 cases of patients, only 3 cases had pneumothorax and 2 cases had slight errhysis in needle passage. The present study showed that the safety of CT-guided fine needle aspiration biopsy was higher than that of coarse needle aspiration biopsy, with much less clinical complications after aspiration. Under the premise of ensuring the rate of detection of certain gene, the utilization of fine needle aspiration biopsy for specimens applicable to fine needle aspiration could not only reach the target of gene detection, but also reduce clinical complications.

Among 250 cases of biopsy specimens of lung cancer, a total of 103 cases were detected to have EGFR gene mutation, with the mutation rate of $41.2 \%$, among which exon 19 deletion (44.7\%) and exon 21 L858R mutation (39.8\%) were common. Among 250 cases of specimens, a total of 15 cases $(6 \%)$ of ALK fusion gene were detected. There were great differences in the rate of EGFR mutation among different races. EGFR mutation rate of Asians was $\sim 30 \%$, which was considerably 
higher than that of Caucasians, $10 \%$. The rate of EGFR mutation in Chinese population was also relatively higher (25). Studies reported that the expression rate of EML4/ALK in unselected NSCLC patients was $<7 \%$, without obvious racial differences (26). Therefore, the rates of EGFR and ALK gene mutation were both in normal range, which had no significant differences with the studies of other scholars.

The detection of the results of EGFR gene mutation showed that the rate of mutation of female patients was significantly higher than that of male patients $(62.1$ and $37.9 \%, \mathrm{P}<0.01)$. The rate of mutation of non-smoking patients was significantly higher than that of smoking patients $(56.2$ and $25 \%, \mathrm{P}<0.01)$. However, age and staging showed no correlation with gene mutation, which was consist with that in most studies (27). In histological types, the rate of EGFR gene mutation in adenocarcinoma $(56.6 \%, \mathrm{P}<0.01)$ was significantly higher than that of squamous carcinoma and other types of lung cancer. Although squamous carcinoma and other types of lung cancer had a lower ratio of EGFR gene mutation, some patients with mutation had their prognosis improved significantly. Therefore, gene detection should also be conducted for patients without adenocarcinoma. In this study, the correlation between the expression of ALK gene and factors including, gender, age and pathological differentiation degree was not found $(\mathrm{P}>0.05)$. Fifteen cases of patients with positive ALK gene were all non-smokers and patients with adenocarcinoma, which was identical to the reports of others (28). Clinical study showed that ALK positive patients, as particular subtype of lung cancer, were characterized by adenocarcinoma, non-smoking, female and younger patients. The expression of ALK gene was also related to some histopathological characteristics, such as dominated by alveolar type, poorly differentiated and positive expression of TTF-1 (29). In our study, the correlation between ALK gene expression and factors, including gender, age and pathological differentiation degree, was not found, which was considered to be mainly related to less patients with positive expression of ALK. We found that the mutation of ALK gene of phase IV patients was significantly higher than that of non-phase IV patients (18.5 and 1.8\%, $\mathrm{P}<0.01$ ), which may be because patients in advanced stage could not be operated on, and needed to specify pathology through aspiration biopsy.

The main objective of this study was to assess factors related to improving the rate of detections of EGFR and ALK gene mutations. The results showed that the rate of detection of EGFR gene was $83.2 \%$ (208/250). The rate of detection of coarse needle biopsy aspiration was higher than that of fine needle (91 and 52\%, $\mathrm{P}<0.01)$ and the positive rate of coarse needle biopsy aspiration was also higher than that of fine needle $(45.5$ and $24 \%, \mathrm{P}<0.01)$. The high rate of detection of coarse needle aspiration was related to that the number of tumor cells by coarse needle aspiration was more than that of tumor cells by fine needle aspiration $(\mathrm{P}<0.05)$, while it was irrelevant to the ratio of tumor cells of coarse and fine needles $(\mathrm{P}>0.05)$. The rate of detection of patients with the number of tumor cells of more than 100 was high. The rate of detection of ALK IHC was 87.2\%. The rate of detection of coarse needle biopsy aspiration was higher than that of fine needle (91 and $72 \%, \mathrm{P}<0.01$ ), but there were no differences in positive rate $(\mathrm{P}>0.05)$. The rate of detection of coarse needle biopsy aspiration was related to the differences in the number of tumor cells of coarse and fine needle aspiration $(\mathrm{P}<0.05)$ and was not related to the ratio of tumor cells of coarse and fine needle aspiration $(\mathrm{P}>0.05)$. Therefore, whether EGFR gene or ALK gene, the main factor that affects the rate of detection is the number of tumor cells. The rate of detection increases with increasing number of tumor cells. Moreover, the more the cases with the number of tumor cells of $\geq 50$ are, the higher the rate of detection is. Whether the ratio of tumor cells was $\geq 10 \%$ had no effects on the rate of detection $(\mathrm{P}>0.05)$ and most specimens complied with the ratio of tumor cells of $\geq 10 \%$. Therefore, the main factor that affected the rate of detection was still the number of tumor cells, which was consistent with other studies $(28,29)$.

Therefore, in case of conducting CT-guided aspiration biopsy gene detection in clinical practical application, it is required to adjust direction with lesion and conduct aspiration at multiple points so as to obtain sufficient specimens and improve the number of tumor cells, thus to increase the success rate of gene detection.

In conclusion, in 250 specimens, the EGFR gene mutation rate was $41.2 \%$ and ALK fusion gene was detected in a total of 15 cases $(6 \%)$. The rate of detections of EGFR gene and ALK gene were 83.2 and $87.2 \%$, respectively. Their rate of detections of coarse biopsy aspiration were higher than those of fine needle, but the rate of detection of fine needle was not low. For patients with only indications of fine needle aspiration, the implementation of cell wax block through fine needle aspiration was still the best choice. Gene rate of detection was related to the number of tumor cells and was not related to the ratio of tumor cells. The rate of detection of patients with the number of tumor cells $\geq 50$ was higher. Therefore, in clinical practical application, in case of conducting CT-guided aspiration biopsy, especial cell wax block embedding by fine needle aspiration biopsy, it is required to adjust direction with lesion and conduct aspiration at multiple points so as to obtain sufficient specimens and improve the number of tumor cells, thus to increase the success rate of gene detection.

\section{References}

1. Molina JR, Yang P, Cassivi SD, Schild SE and Adjei AA: Non-small cell lung cancer: epidemiology, risk factors, treatment, and survivorship. Mayo Clin Proc 83: 584-594, 2008.

2. Chen W, Zheng R, Zeng H and Zhang S: Epidemiology of lung cancer in China. Thorac Cancer 6: 209-215, 2015.

3. Henschke CI, McCauley DI, Yankelevitz DF, Naidich DP, McGuinness G, Miettinen OS, Libby DM, Pasmantier MW, Koizumi J, Altorki NK, et al: Early Lung Cancer Action Project: overall design and findings from baseline screening. Lancet 354 : 99-105, 1999

4. Dimitroulis J and Stathopoulos GP: Evolution of non-small cell lung cancer chemotherapy (Review). Oncol Rep 13: 923-930, 2005.

5. Donati V, Fontanini G and Dell'Omodarme M, Prati MC, Nuti S, Lucchi M, Mussi A, Fabbri M, Basolo F, Croce CM, et al: WWOX expression in different histologic types and subtypes of non-small cell lung cancer. Clin Cancer Res 13: 884-891, 2007.

6. Simon G, Sharma A and Li X, Hazelton T, Walsh F, Williams C, Chiappori A, Haura E, Tanvetyanon T, Antonia S, et al: Feasibility and efficacy of molecular analysis-directed individualized therapy in advanced non-small-cell lung cancer. J Clin Oncol 25: 2741-2746, 2007.

7. Ma PC: Personalized targeted therapy in advanced non-small cell lung cancer. Cleve Clin J Med 79 (Electronic Suppl 1): eS56-eS60, 2012. 
8. Zhu Z and Chai Y: Complete remission of liver metastasis in a lung cancer patient with epidermal growth factor mutation achieved with Icotinib. Thorac Cancer 7: 681-683, 2016.

9. Kwak EL, Bang YJ, Camidge DR, Shaw AT, Solomon B, Maki RG, Ou SH, Dezube BJ, Jänne PA, Costa DB, et al: Anaplastic lymphoma kinase inhibition in non-small-cell lung cancer. N Engl J Med 363: 1693-1703, 2010.

10. Watanabe S, Tanaka J, Ota T, Kondo R, Tanaka H, Kagamu H, Ichikawa K, Koshio J, Baba J, Miyabayashi T, et al: Clinical responses to EGFR-tyrosine kinase inhibitor retreatment in non-small cell lung cancer patients who benefited from prior effective gefitinib therapy: a retrospective analysis. BMC Cancer 11: 1, 2011.

11. Shaw AT, Yeap BY, Solomon BJ, Riely GJ, Gainor J, Engelman JA, Shapiro GI, Costa DB, Ou SH, Butaney M, et al Effect of crizotinib on overall survival in patients with advanced non-small-cell lung cancer harbouring ALK gene rearrangement: a retrospective analysis. Lancet Oncol 12: 1004-1012, 2011.

12. Fukuoka M, Wu Y, Thongprasert S, Yang C, Chu D, Saijo N, Watkins C, Duffield E, Armour A and Mok T: Biomarker analyses from a phase III, randomized, open-label, first-line study of gefitinib $(\mathrm{G})$ versus carboplatin/paclitaxel $(\mathrm{C} / \mathrm{P})$ in clinically selected patients (pts) with advanced non-small cell lung cancer (NSCLC) in Asia (IPASS). J Clin Oncol (ASCO Annual Meeting) 27: Abst 8006, 2009.

13. Mitsudomi T, Morita S, Yatabe Y, Negoro S, Okamoto I, Tsurutani J, Seto T, Satouchi M, Tada H, Hirashima T, et al; West Japan Oncology Group: Gefitinib versus cisplatin plus docetaxel in patients with non-small-cell lung cancer harbouring mutations of the epidermal growth factor receptor (WJTOG3405): an open label, randomised phase 3 trial. Lancet Oncol 11: 121-128, 2010.

14. Gainor JF, Sherman CA, Willoughby K, Logan J, Kennedy E, Brastianos PK, Chi AS and Shaw AT: Alectinib salvages CNS relapses in ALK-positive lung cancer patients previously treated with crizotinib and ceritinib. J Thorac Oncol 10 232-236, 2015

15. Nakajima T, Yasufuku K, Suzuki M, Hiroshima K, Kubo R, Mohammed S, Miyagi Y, Matsukuma S, Sekine Y and Fujisawa T: Assessment of epidermal growth factor receptor mutation by endobronchial ultrasound-guided transbronchial needle aspiration. Chest 132: 597-602, 2007.

16. Sakairi Y, Nakajima T, Yasufuku K, Ikebe D, Kageyama H, Soda M, Takeuchi K, Itami M, Iizasa T, Yoshino I, et al EML4-ALK fusion gene assessment using metastatic lymph node samples obtained by endobronchial ultrasound-guided transbronchial needle aspiration. Clin Cancer Res 16 4938-4945, 2010.

17. Duan H, Lu J, Lu T, Gao J, Zhang J, Xu Y, Wang M, Wu H, Liang $\mathrm{Z}$ and Liu T: Comparison of EGFR mutation status between plasma and tumor tissue in non-small cell lung cancer using the Scorpion ARMS method and the possible prognostic significance of plasma EGFR mutation status. Int J Clin Exp Pathol 8: 13136-13145, 2015.
18. Togashi Y, Soda M, Sakata S, Sugawara E, Hatano S, Asaka R, Nakajima T, Mano $\mathrm{H}$ and Takeuchi K: KLC1-ALK: A novel fusion in lung cancer identified using a formalin-fixed paraffin-embedded tissue only. PLoS One 7: e31323, 2012.

19. Yi ES, Boland JM, Maleszewski JJ, Roden AC, Oliveira AM, Aubry MC, Erickson-Johnson MR, Caron BL, Li Y, Tang H, et al: Correlation of IHC and FISH for ALK gene rearrangement in non-small cell lung carcinoma: IHC score algorithm for FISH. J Thorac Oncol 6: 459-465, 2011.

20. Ying J, Guo L, Qiu T, Shan L, Ling Y, Liu X and Lu N: Diagnostic value of a novel fully automated immunochemistry assay for detection of ALK rearrangement in primary lung adenocarcinoma. Ann Oncol 24: 2589-2593, 2013.

21. Lee JK, Kim TM, Koh Y, Lee SH, Kim DW, Jeon YK, Chung DH, Yang SC, Kim YT, Kim YW, et al: Differential sensitivities to tyrosine kinase inhibitors in NSCLC harboring EGFR mutation and ALK translocation. Lung Cancer 77: 460-463, 2012.

22. Li H, Boiselle PM, Shepard JO, Trotman-Dickenson B and McLoud TC: Diagnostic accuracy and safety of CT-guided percutaneous needle aspiration biopsy of the lung: comparison of small and large pulmonary nodules. AJR Am J Roentgenol 167: 105-109, 1996.

23. Soria JC, Massard C and Le Chevalier T: Should progressionfree survival be the primary measure of efficacy for advanced NSCLC therapy? Ann Oncol 21: 2324-2332, 2010

24. Nakahara Y, Mochiduki Y, Miyamoto Y, Nakahara Y and Katsura Y: Prognostic significance of the lymphocyte-toneutrophil ratio in percutaneous fine-needle aspiration biopsy specimens of advanced nonsmall cell lung carcinoma. Cancer 104: 1271-1280, 2005

25. Rubin BP, Heinrich MC and Corless CL: Gastrointestinal stromal tumour. Lancet 369: 1731-1741, 2007.

26. Soda M,Choi YL,Enomoto M,Takada S, Yamashita Y,Ishikawa S, Fujiwara S, Watanabe H, Kurashina K, Hatanaka H, et al: Identification of the transforming EML4-ALK fusion gene in non-small-cell lung cancer. Nature 448: 561-566, 2007.

27. Ciardiello $\mathrm{F}$ and Tortora G: EGFR antagonists in cancer treatment. N Engl J Med 358: 1160-1174, 2008.

28. Inamura $\mathrm{K}$, Takeuchi $\mathrm{K}$, Togashi $\mathrm{Y}$, Hatano $\mathrm{S}$, Ninomiya $\mathrm{H}$, Motoi N, Mun MY, Sakao Y, Okumura S, Nakagawa K, et al: EML4-ALK lung cancers are characterized by rare other mutations, a TTF-1 cell lineage, an acinar histology, and young onset. Mod Pathol 22: 508-515, 2009.

29. Shaw AT, Yeap BY, Mino-Kenudson M, Digumarthy SR, Costa DB, Heist RS, Solomon B, Stubbs H, Admane S, McDermott U, et al: Clinical features and outcome of patients with non-small-cell lung cancer who harbor EML4-ALK. J Clin Oncol 27: 4247-4253, 2009 